\title{
Job Satisfaction and Organizational Commitment among Employees in the Sultanate of Oman
}

\section{Syed Mohammad Azeem}

Department of Management Information Systems, Yanbu University College, Yanbu, Saudi Arabia. Email: azeem_syed@hotmail.com

Received August $9^{\text {th }}, 2010$; revised August 21 ${ }^{\text {st }}, 2010$; accepted August $26^{\text {th }}, 2010$.

\begin{abstract}
This study investigated the nature of relationships of demographic factors (age and job tenure) and job satisfaction facets with organizational commitment. The study also sought to determine the impact of demographic factors and job satisfaction facets on organizational commitment. A sample consists of 128 employees from service industry selected randomly. Employees were given a Job Descriptive Index (JDI) questionnaire and the Organizational Commitment questionnaire (OCQ). Pearson's product moment correlation coefficient and multiple regression analyses were used to analyze the data. The Results of the study show that the mean values of job satisfaction and organizational commitment are at moderate side. A moderate significant positive relationship was found among job satisfaction facets, demographic factors, and organizational commitment. Supervision, pay, overall job satisfaction, age, and job tenure were the significant predictors of organizational commitment.
\end{abstract}

Keywords: Job Satisfaction, Organizational Commitment, Correlation, Oman

\section{Introduction}

Organizational commitment and job satisfaction are job related attitudes that have received considerable attention from researchers around the globe. This is because committed and satisfied employees are normally high performers that contribute towards organizational productivity [1-3].

There are not much research efforts taken to explore attitudinal and behavioral aspects in the Sultanate of Oman. This study initiates an attempt to address this issue. This study is intended to examine the level of job satisfaction and organizational commitment among employees in the selected organizations in Muscat, Oman.

The success of an organization and the pursuit of quality depend not only on how the organization makes the most of human competencies, but also on how it stimulates commitment to an organization [4,5]. Commitment has been related to valuable outcomes for both employees and employers. Greater commitment can result in enhanced feelings of belonging, security, efficacy, greater career advancement, increased compensation and increased intrinsic rewards for the individual [6]. For the organization, the rewards of commitment can mean increased employee tenure, limited turnover, reduced training costs, greater job satisfaction, acceptance of organi- zation's demands, and the meeting of organizational goals such as high quality [7].

Different authors depending on their backgrounds have defined and measured organizational commitment differently. According to organizational commitment can be defined as an employee's level of identification and involvement in the organization [8]. For Meyer and Allens organizational commitment is a psychological state that characterizes the employee's relationship with the organization with its implications for the decision to continue membership in the organization [9]. Mowday et al. defined organizational commitment as a strong belief in an organization's goals, and values, a willingness to exert considerable effort on behalf of an organization and a strong desire to remain a member of the organization [7].

Demographic factors such as age, gender, marital status, education level and work experience have found to be significantly related to organizational commitment [10-13]. However, Salami found that age and job tenure are significant predictors of organizational commitment [14].

Luthans [15] defined job satisfaction as a pleasurable or positive emotional state resulting from the appraisal of one's job or job experience. It is a result of employee's perception of how well their job provides those things 
that are viewed as important. Evan [16] defined job satisfaction as a state of mind encompassing all those feelings determined by the extent to which the individual perceives his/her job-related needs to be being met. Mowday et al. [7] defined job satisfaction as the relative strength of an individual's identification with and involvement in a particular organization.

It is evident that there are numerous definitions of the construct "organizational commitment”. For the purposes of this study, it is the definition of Mowday et al. [7] that will be used.

Several researchers have reported mixed findings on the relationship between job satisfaction and organizational commitment. For instance, Curry, Wakefield, Price and Mueller [17] found no significant relationship between the two. However, other researchers [11,14,18-21]. Many studies use different facets of job satisfaction to predict organizational commitment [22-24].

\section{Purpose of the Study}

The purpose of this study was to investigate the relationship between job satisfaction facets and demographic variables (age and job tenure) with organizational commitment and the extent these variables can be the determinant of organizational commitment among employees selected in the sample.

\subsection{Hypotheses}

Based on the literature discussed this study attempted to answer the following questions:

1) There will be positive and significant relationship between Job satisfaction facets and organizational commitment.

2) Demographic variables (age and job Tenure) and job satisfaction facets will significantly predict organizational commitment of the employees in the sample.

\section{Method}

\subsection{Participants}

A sample of 128 employees was randomly selected from 5 service organizations in Muscat.

\subsection{Measures}

Biographical Information Sheet: The biographical data information sheet was used to collect information on the participants’ age and job tenure.

Job Satisfaction: Job satisfaction was measured with the aid of Job Descriptive Index (JDI), developed by Smith et al. [2]. The JDI has probably been the most popular facet scale among organizational researchers and attempts to study employee reactions to several aspects or facets of the job.
These include:

- $\quad$ Nature and content of the job;

- Pay;

- Supervision;

- $\quad$ Promotion opportunities;

- Relationships with co-workers.

The entire scale consists of 72 items. Each subscale is described by 18 evaluative adjectives, which is descriptive of the job, except compensation and opportunities for advancement, which consists of 9 items each. Both favorable or positively worded and unfavorable or negatively worded items are provided. Respondents are required to consider each of the items and decide whether it is applicable to them or not. The respondents mark "Y" if the item is applicable, "N" if it is not applicable and "?" if they are uncertain. Each dimension's score is calculated by weighting the positive items as $\mathrm{Y}=3, ?=2$ and $\mathrm{N}=1$ and the negative items as $\mathrm{Y}=1, ?=2$ and $\mathrm{N}=3$.

Organizational Commitment: The Most commonly used instrument to measure organizational commitment, is the organizational commitment questionnaire (OCQ) developed by Mowday et al. [7]. The OCQ is a 15-statement instrument, which uses a 7-point scale from "strongly disagree" to "strongly agree”. Statements are directed at the 3 elements of a strong belief and acceptance of the organization's goals and values, a willingness to exert considerable effort and a strong desire to maintain membership. Nine (9) of the statements are positively worded and six are negatively worded and reverse scored to reduce response bias [7]. The results are summed and divided by 15 to produce a summary indicator of organizational commitment.

\subsection{Procedure}

Two self-administered questionnaires were personally distributed randomly to the respondents with a covering letter, detailing the nature of the study and assurances of confidentiality. Detailed instructions were provided to respondents on how questionnaires were to be completed and returned.

\section{Results}

The statistical methods used to test the research hypotheses include mean, standard deviation, product moment correlation coefficients, and regression analysis.

Descriptive statistics are presented in Table $\mathbf{1}$ to describe the profile and salient characteristics of the sample in relation to the variables included in the study.

With respect to the dimensions of job satisfaction assessed by the JDI for respondents, Table 1 indicates that the arithmetic means for the nature of the work, supervision and co-worker subscales are 42.24, 44.19 and 41.83 
Table 1. Descriptive statistics for the dimensions of job satisfaction and organizational commitment.

\begin{tabular}{ccccc}
\hline Variable & Mean & S.D. & Min & Max \\
\hline Organizational Commitment & 77.73 & 16.16 & 37 & 105 \\
Work Sub Scale & 42.24 & 6.4 & 29 & 52 \\
Supervision Subscale & 44.19 & 7.85 & 18 & 54 \\
Co-workers Sub Scale & 41.83 & 9.1 & 24 & 58 \\
Promotion Sub Scale & 20.9 & 7.8 & 11 & 27 \\
Pay Sub Scale & 19.17 & 4.8 & 9 & 27 \\
Overall Job Satisfaction & 213.20 & 30.86 & 136 & 262 \\
\hline
\end{tabular}

respectively. An approximate mean of 36 constitutes an average level of satisfaction on these subscales. It therefore appears that employees in the sample are relatively satisfied with the nature of the work that they perform, with their coworkers and satisfied with the supervision they receive.

Means of 20.9 and 19.17 were obtained for the promotion and pay subscales respectively. Average levels of satisfaction on these subscales are represented by an approximate mean score of 18 . It would thus appear that employees in the sample are relatively satisfied with their promotion opportunities and the pay they receive.

Furthermore, Table 1 indicates that the arithmetic mean and standard deviation for the organizational commitment of the sample are 77.73 and 16.16 respectively. As a mean score of approximately 60 would constitute an average level of organizational commitment, it may be concluded that employees in the sample demonstrate high levels of organizational commitment as assessed by the OCQ, although the standard deviation is slightly high which shows that the scores are not distributed very closely to the mean.

The Pearson's Product Moment Correlation Coefficient was computed for the purposes of determining the following relationships:

Table 2. Correlation between Job satisfaction facets and demographic variables with organizational commitment.

\begin{tabular}{ccc}
\hline S.No. & Variables & Organizational Commitment \\
\hline 1 & Work Sub Scale & $0.458^{* *}$ \\
2 & Supervision Subscale & $0.487^{* *}$ \\
3 & Co-workers Sub Scale & $0.393^{* *}$ \\
4 & Promotion Sub Scale & $0.366^{* *}$ \\
5 & Pay Sub Scale & $0.211^{*}$ \\
6 & Overall Job Satisfaction & $0.560^{* *}$ \\
7 & Age & $0.28^{*}$ \\
8 & Job Tenure & $0.26^{*}$ \\
\hline
\end{tabular}

** Correlation is significant at the 0.01 level ( 2 tailed); *Correlation is significant at the 0.05 level ( 2 tailed)
Results from Table 2 revealed that there are positive relationships between job satisfaction facets and organizational commitment. The results indicated support for the first hypothesis as all the facets of job satisfaction are significantly related with organizational commitment at 0.01 and 0.05 level. There was a weak positive relationship between age and organizational commitment $(r=$ $0.28, \mathrm{p}<0.05$ ). Similarly a positive relationship was found between job tenure and organizational commitment $(\mathrm{r}=0.26, \mathrm{p}<0.05)$.

The coefficient correlation of job satisfaction facets and overall job satisfaction were $0.45,0.48,0.39,0.36$, 0.21 and 0.56 respectively. This indicates that the strength of the relationship was moderate and substantial. The low relationships were found with co-workers $(r=0.39)$, promotion $(\mathrm{r}=0.36)$, and pay $(\mathrm{r}=0.21)$.

There is a statistically significant positive relationship between job satisfaction and organizational commitment $(r=0.56 ; p=0.00)$ for the sample. This would seem to imply that if the job satisfaction were to change, then organizational commitment would change accordingly. The coefficient of determination, $\left(r^{2}=0.31\right)$, implies that $31 \%$ of the variation in organizational commitment of the sample can be attributed to job satisfaction. The remaining $69 \%$ can be explained by other variables. The correlation shows that high level of organizational commitment is not just because of high job satisfaction level but some other strong variables are there for this. The results confirm the first hypothesis.

The second hypothesis as to determine whether demographical variables (age and Job tenure) and each of the job satisfaction facets are the significant determinants of organizational commitment, stepwise regression analysis was carried out.

Results from the Table 3 indicate that only overall job satisfaction, supervision, and pay (adjusted $\mathrm{R}=0.37, \mathrm{~F}=$ $11.98, \mathrm{P}<0.05$ ) have contributed toward the $\mathrm{R}^{2}$ value. Based on the $\mathrm{R}$ square value of 0.371 , these facets of job satisfaction could explain $37.1 \%$ in the variation of employees' organizational commitment. Demographic variables (age and job tenure) used in the study are predicting organizational commitment (adjusted $\mathrm{R}=0.03, \mathrm{~F}=3.2$ ).

\section{Conclusions}

The results from the study indicated that age and job tenure significantly predicted organizational commitment. These results are consistent with previous studies that older workers have more commitment to their organizations than the younger ones [10]. Age and job tenure were found significant predictors of organizational commitment may be because the longer the employees stay with an organization the more time they have to understand the organization and their relationship with it. 
Table 3. Regression analysis of Job satisfaction facets and demographic variables with organizational commitment.

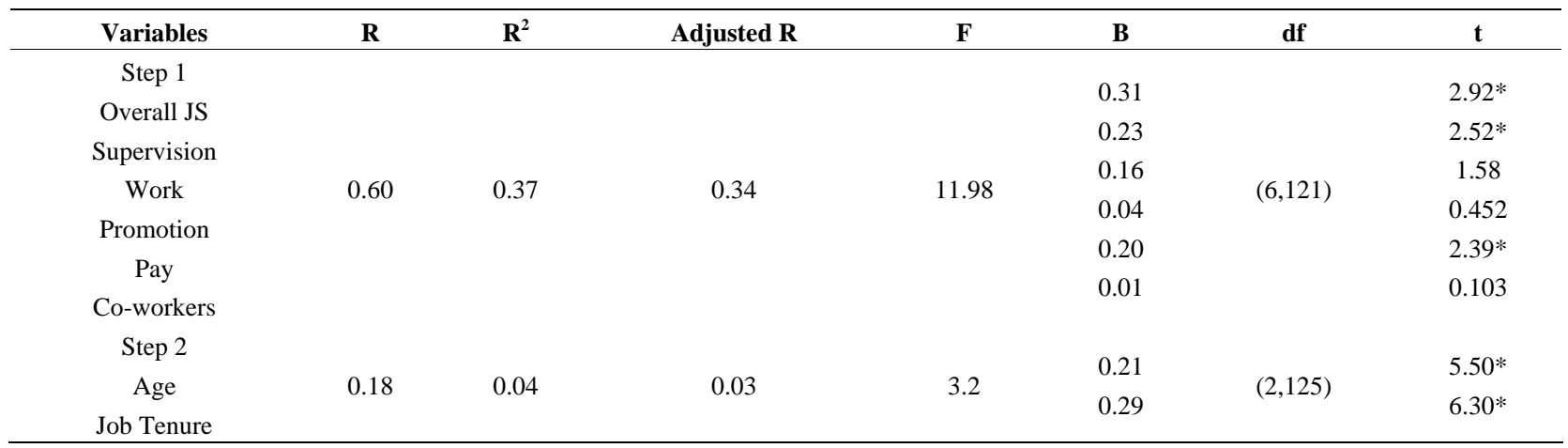

$* \mathbf{P}<\mathbf{0 . 0 5}$

Job satisfaction and some of its facets are found as significant predictors of organizational commitment. These finding are supported by earlier researcher who found that job satisfaction was a significant predictor of organizational commitment [11,18-24]. Second hypothesis has also been confirmed through the results

\section{Implications and Limitations of the Findings}

This study has contributed to the existing theory of organizational behavior and is useful for research purpose. The findings are also very informative in explaining and solving problems related to behavioral aspects of organizations particularly factors that contribute towards organizational commitment among employees.

Findings of the study suggest that organizations should consider some factors that have been identified to have strong impact on organizational commitment and incorporate them in employees' development programs to improve their attitude in the workplace. Furthermore, the findings of this study can be of great help in designing polices for improving organizational commitment.

It is the initial stage of behavioral research in the area. In future an in depth study is required to be conducted to identify other factors which contribute to organizational commitment.

\section{REFERENCES}

[1] T. Oshagbemi, "Job Satisfaction and Dissatisfaction in Higher Education,” Education \& Training, Vol. 39, No. 9, 1997a, pp. 354-359.

[2] P. C. Smith, L. M. Kendallt and C. L. Hulin, “The Measurement of Satisfaction in Work and Retirement,” Rand Mc Nally, Chicago, 1969.

[3] D. A. Yousef, “Organizational Commitment: A Mediator of the Relationships of Leadership Behavior with Job Satisfaction and Performance in a Non-Western Country,” Journal of Managerial Psychology, Vol. 15, No. 1,
2000, pp. 6-24.

[4] G. Beukhof, M. J. de Jong and W. J. Nijhof, "Employee Commitment in Changing Organization: An Exploration,” Journal of European Industrial Training, Vol. 22, No. 6, 1998, pp. 243-248.

[5] A. Thornhill, P. Lewis and M. N. K. Saunders, "The Role of Employee Communication in Achieving Commitment and Quality in Higher Education,” Quality Assurance in Education, Vol. 4, No. 1, 1996, pp. 12-20.

[6] R. W. Rowden, "The Relationship between Charismatic Leadership Behaviors and Organizational Commitment," Leadership \& Organization Development Journal, Vol. 21, 2000, pp. 30-35.

[7] R. T. Mowday, L. W. Porter and R. M. Steers, "Employee-Organization Linkages: The Psychology of Commitment, Absenteeism and Turnover,” Academic Press, Inc., New York, 1982.

[8] L. T. Mullins, "Management and Organizational Behaviour,” 5th Edition, Financial Times Management, London, 1999.

[9] J. Meyer and N. Allen, "Commitment in the Workplace," SAGE Publications, Thousand Oaks, 1997.

[10] D. Dodd-McCue and G. B. Wright, "Men, Women and Attitudinal Commitment: The Effects of Workplace Experiences and Socialization," Human Relations, Vol. 49, No. 8, 1996, pp. 1065-1089.

[11] B. Mannheim, Y. Baruch and J. Tal, “Alternative Models for Antecedents and Outcomes of Work Centrality and Job Satisfaction of High-Tech Personnel," Human Relations, Vol. 50, No. 12, 1997, pp. 1537-1562.

[12] P. Morrow, "The Theory and Measurement of Work Commitment,” JAL Press, Greenwich, 1993.

[13] S. M. Wiedmer, "An Examination of Factors Affecting Employee Satisfaction,” 1998. http://clearinghouse.missouriwestern.edu/manuscripts/51.asp

[14] S. O. Salami, "Demographic and Psychological Factors Predicting Organizational Commitment among Industrial Workers,” Anthropologist, Vol. 10, No. 1, 2008, pp. 3138.

[15] E. Luthans, “Organizational Behavior,” Irwin/McGraw- 
Hill, New York, 1998.

[16] L. Evans, "Delving Deeper into Morale, Job Satisfaction and Motivation among Education Professionals: ReExamining the Leadership Dimension,” Educational Management and Administration, Vol. 29, No. 3, 2001, pp. 291-306.

[17] J. Curry, D. Wakefield, J. Price and C. Mueller, "On the Causal Ordering of Job Satisfaction and Organizational Commitment," Academy of Management Journal, Vol. 29, No. 4, 1986, pp. 847-858.

[18] T. Busch, L. Fallan and A. Pettersen, "Disciplinary Differences in Job Satisfaction Self-Efficacy, Goal Commitment and Organizational Commitment among Faculty Employees in Norwegian Colleges: An Empirical Assessment of Indicators of Performance," Quality in Higher Education, Vol. 4, No. 2, 1998, pp. 137-157.

[19] T. Chiu-Yueh, “A Sudy on the Relationship among Organizational Commitment, Job Satisfaction and Organizational Citizenship Behaviour of Nursing Personnel,” Unpublished Master's Thesis, Department of Human Re- source Management, 2000. http://etd.lib.nsusu

[20] A. H. Feinstein and D. Vondrasek, "A Study of Relationship between Job Satisfaction and Organizational Commitment among Restaurant Employees,” 2006. http://hotel.unlv.edu/pdf/jobSatisfaction.pdf

[21] A. Freund, "Commitment and Job Satisfaction as Predictors Turnover Intentions among Welfare Workers,” Administration in Social Work, Vol. 29, No. 2, 2005, pp. 521.

[22] J. R. Dienhart and M. B. Gregoire, "Job Satisfaction, Job Involvement, Job Security, and Customer Focus of Quick-Service Restaurant Employees,” Hospitality Research Journal, Vol. 16, No. 2, 1993, pp. 29-44.

[23] T. Oshagbemi, "Correlates of Pay Satisfaction in Higher Education," International Journal of Educational Management, Vol. 14, No. 1, 2000a, pp. 31-39.

[24] D. A. Yousef, "Satisfaction with Job Security as a Predictor of Organizational Commitment and Job Performance in a Multicultural Environment," International Journal of Manpower, Vol. 19, No. 3, 1998, pp. 184-194. 